\title{
Communities Support Engineering as a College Major Choice
}

\section{Stacey L. Vaziri, Virginia Tech Department of Engineering Education}

Stacey Vaziri is a PhD candidate in the Department of Engineering Education at Virginia Tech. She received her M.S. in Materials Engineering from Purdue University and her B.S. in Chemical Engineering from North Carolina State University. Her research interests include access to higher education and broadening participation in engineering.

\section{Dr. Marie C Paretti, Virginia Polytechnic Institute and State University}

Marie C. Paretti is a Professor of Engineering Education at Virginia Tech, where she directs the Virginia Tech Engineering Communications Center (VTECC). Her research focuses on communication in engineering design, interdisciplinary communication and collaboration, design education, and gender in engineering. She was awarded a CAREER grant from the National Science Foundation to study expert teaching in capstone design courses, and is co-PI on numerous NSF grants exploring communication, design, and identity in engineering. Drawing on theories of situated learning and identity development, her work includes studies on the teaching and learning of communication, effective teaching practices in design education, the effects of differing design pedagogies on retention and motivation, the dynamics of cross-disciplinary collaboration in both academic and industry design environments, and gender and identity in engineering.

\section{Dr. Jacob R Grohs, Virginia Polytechnic Institute and State University}

Jacob Grohs is an Assistant Professor in Engineering Education at Virginia Tech with Affiliate Faculty status in Biomedical Engineering and Mechanics and the Learning Sciences and Technologies at Virginia Tech. He holds degrees in Engineering Mechanics (BS, MS) and in Educational Psychology (MAEd, $\mathrm{PhD})$.

\section{Dr. Liesl M Baum, Virginia Polytechnic Institute and State University}

Dr. Liesl Baum is the Associate Director for Professional Development at the Center for Excellence in Teaching and Learning. She is a former middle school teacher and spent seven years teaching in Virginia public schools. Her research interests and goals are to develop a frame of mind that allows for creativity to develop among students and faculty of all levels. She works with university faculty to identify and build teaching strategies that encourage creativity for learning. Her research and work interests remain across the full realm of education and preparing educators to design and develop teaching and learning opportunities that encourage students to take risks, inquire across multiple disciplines, and participate in grand challenges. Liesl received her B.S. in Middle Education and M.S. in Educational Technology, both from Radford University. She received her doctorate in instructional design and technology from Virginia Tech.

\section{Dr. Marlena McGlothlin Lester, Virginia Tech}

Marlena McGlothlin Lester is the Director of Advising for the Department of Engineering Education at Virginia Tech. She leads the undergraduate advising team and oversees the advising process for all General Engineering students. She is responsible for the development of a hands-on, minds-on orientation model for all first-year engineering students, the creation of a comprehensive engineering major exploration tool, Explore Engineering, and enhancement of the academic planning resources available for first-year engineering students. Marlena strives to transform the advising experience for students and advisors through communication, collaboration, and consistency.

\section{Dr. Phyllis Leary Newbill}

Dr. Phyllis Newbill is the Outreach and Engagement Coordinator at the Institute for Creativity, Arts, and Technology (ICAT) at Virginia Tech. She serves as the liaison between the university and the Science 
Museum of Western Virginia and directs the Virginia Tech Science Festival. She has worked in science education at preschool, high school, university, and adult education levels. She has both formal and informal instructional experience. Her research interests include museum learning, science education, critical and creative thinking, outdoor education, gender issues in education, rural education, and incorporating the arts into standards-based instruction. She received a double B.S. in Geology and English from Radford University in 1998. She received her M.S. In Environmental and Engineering Geosciences from Radford University in 2001. She earned her Ph.D. from Virginia Tech in Instructional Design and Technology in 2005. Phyllis has worked with ICAT and its prototypes since 2007. 


\title{
Community Cultures: Broadening Participation by Understanding How Rural Communities Support Engineering as a College Major Choice
}

\begin{abstract}
Project funded by the Division of Engineering Education and Centers (EEC)

Broadening participation in engineering is critical given the gap between the nation's need for engineering graduates and its production of them. Efforts to spark interest in engineering among PreK-12 students have increased substantially in recent years as a result. However, past research has demonstrated that interest is not always sufficient to help students pursue engineering majors, particularly for rural students. In many rural communities, influential adults (family, friends, teachers) are often the primary influence on career choice, while factors such as community values, lack of social and cultural capital, limited course availability, and inadequate financial resources act as potential barriers. To account for these contextual factors, this project shifts the focus from individual students to the communities to understand how key stakeholders and organizations support engineering as a major choice and addresses the following questions:
\end{abstract}

RQ1. What do current undergraduate engineering students who graduated from rural high schools describe as influences on their choice to attend college and pursue engineering as a post-secondary major?

RQ2. How does the college choice process differ for rural students who enrolled in a 4-year university immediately after graduating from high school and those who transferred from a 2-year institution?

RQ3. How do community members describe the resources that serve as key supports as well as the barriers that hinder support in their community?

RQ4. What strategies do community members perceive their community should implement to enhance their ability to support engineering as a potential career choice?

RQ5. How are these supports transferable or adaptable by other schools? What community-level factors support or inhibit transfer and adaptation?

To answer the research questions, we employed a three-phase qualitative study. Phase 1 focused on understanding the experiences and perceptions of current [University Name] students from higher-producing rural schools. Analysis of focus group and interview data with 52 students highlighted the importance of interest and support from influential adults in students' decision to major in engineering. One key finding from this phase was the importance of community college for many of our participants. Transfer students who attended community college before enrolling at [University Name] discussed the financial influences on their decision and the benefits of higher education much more frequently than their peers. In Phase 2, we used the findings from Phase 1 to conduct interviews within the participants' home communities. This phase helped triangulate students' perceptions with the perceptions and practices of others, and, equally importantly, allowed us to understand the goals, attitudes, and experiences of school personnel 
and local community members as they work with students. Participants from the students' home communities indicated that there were few opportunities for students to learn more about engineering careers and provided suggestions for how colleges and universities could be more involved with students from their community. Phase 3, scheduled for Spring 2020, will bring the findings from Phases 1 and 2 back to rural communities via two participatory design workshops. These workshops, designed to share our findings and foster collaborative dialogue among the participants, will enable us to explore factors that support or hinder transfer of findings and to identify policies and strategies that would enhance each community's ability to support engineering as a potential career choice.

\section{Project Overview}

Despite continued outreach and recruitment efforts, current rates of engineering enrollment are not sufficient to meet the nation's growing need for technical and engineering graduates. Recent efforts to address this problem aim to increase interest in engineering among PreK-12 students. However, past research demonstrates that interest is not always sufficient to help students pursue engineering majors, particularly for rural students [1]. Influential adults (family, friends, teachers) are often the primary influence on rural students' college and career choices, while factors such as strong family and community bonds, lack of social and cultural capital, limited access to advanced courses, and inadequate financial resources often limit their postsecondary education choices $[2,3]$. Given the unique geographic and cultural factors, it is critical to study rural students' college and career choice in context. Thus, this project focuses on rural communities to understand how key stakeholders and organizations support engineering as a major choice and addresses the following questions:

RQ1. What do current undergraduate engineering students who graduated from rural high schools describe as influences on their choice to attend college and pursue engineering as a post-secondary major?

RQ2. How does the college choice process differ for rural students who enrolled in a 4-year university immediately after graduating from high school and those who transferred from a 2-year institution?

RQ3. How do community members describe the resources that serve as key supports as well as the barriers that hinder support in their community?

RQ4. What strategies do community members perceive their community should implement to enhance their ability to support engineering as a potential career choice?

RQ5. How are these supports transferable or adaptable by other schools? What community-level factors support or inhibit transfer and adaptation?

To address these research questions, we employed a three-phase qualitative study shown in Figure 1. The first two phases targeted rural high schools in the study region that consistently send students to [University Name] as engineering majors. Phase 1 focused on alumni from these schools currently enrolled in undergraduate engineering at [University Name] (RQ1 and RQ2); Phase 2 focused on these students' high schools and home communities (RQ3 and RQ4). Finally, in Phase 3 we plan to employ participatory design workshops to share findings from the first two 
phases with relevant groups who work with students from rural Appalachian counties. These workshops, designed to foster dialogue across rural communities, will enable us to explore factors that support or hinder transfer of findings and to identify policies and strategies that would enhance each community's ability to support engineering as a potential career choice (RQ5).

\begin{tabular}{|l|l|l|l|}
\hline $\begin{array}{l}\text { Phase 1 } \\
\text { Understanding Student } \\
\text { Experiences }\end{array}$ & $\begin{array}{l}\text { Phase 2 } \\
\text { Qualitative focus groups and } \\
\text { interviews with undergraduate } \\
\text { engineering students who } \\
\text { graduated from targeted rural high } \\
\text { schools in Virginia }\end{array}$ & $\begin{array}{l}\text { Perspectives } \\
\text { Interviews with key individuals } \\
\text { (e.g. guidance counselors, teachers, } \\
\text { relevant members of town } \\
\text { government) and observations of } \\
\text { salient activities }\end{array}$ \\
\hline
\end{tabular}

Figure 1. Study Phases

\section{Conceptual Framework}

Perna's conceptual model of student college choice, shown in Figure 2, was used to frame this study [4]. Perna's model draws on both economic and sociological approaches to decision making. At the center of Perna's model is an economic model of human capital investment often used to examine students' college choices. Human capital theory assumes that students' college-choice decisions are based on their evaluation of the expected benefits and costs of investing in higher education. Although economic approaches relying on human capital theory are useful for understanding decision making, they are limited by their failure to consider that students have differential access to information about college. Thus, Perna's model nests the human capital investment model within four layers of context: (1) the individual's habitus, (2) the school and community context, (3) higher education context, and (4) the social, economic, and policy context. 


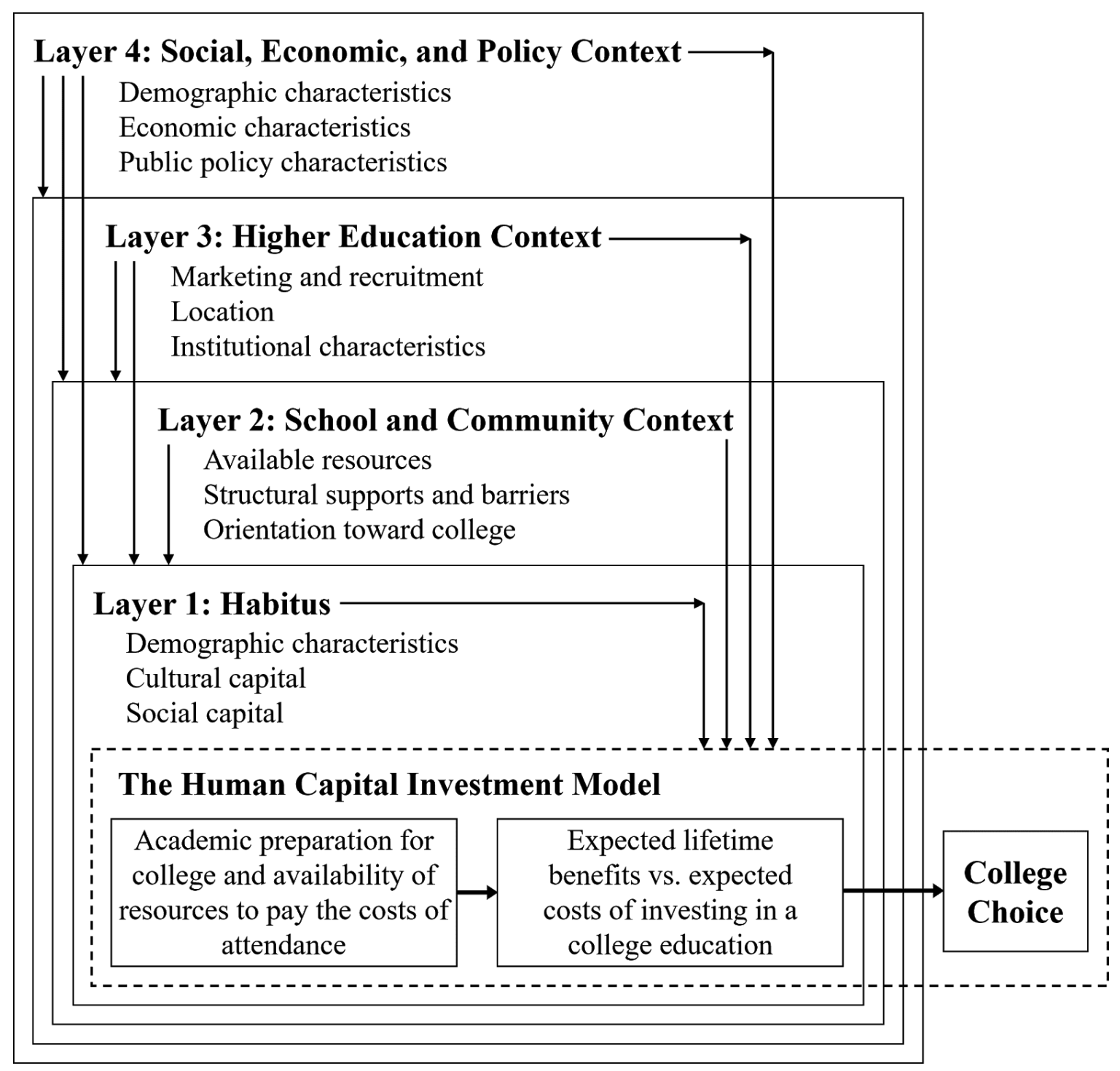

Figure 2. Perna's Conceptual Model of Student College Choice [4]

\section{Phase 1: Understanding Student Experiences}

Phase 1 focused on undergraduate engineering students who graduated from targeted rural high schools and aimed to identify key influences on their decision to attend college and major in engineering. In addition, this study compared the college choice process of community college transfer students and students who enrolled in a four-year university immediately after high school. Following Yin [5], we conducted a single-case study with embedded units, in which the case is the college choice process of undergraduate engineering students from rural high schools (see Figure 3 for a visual description). 


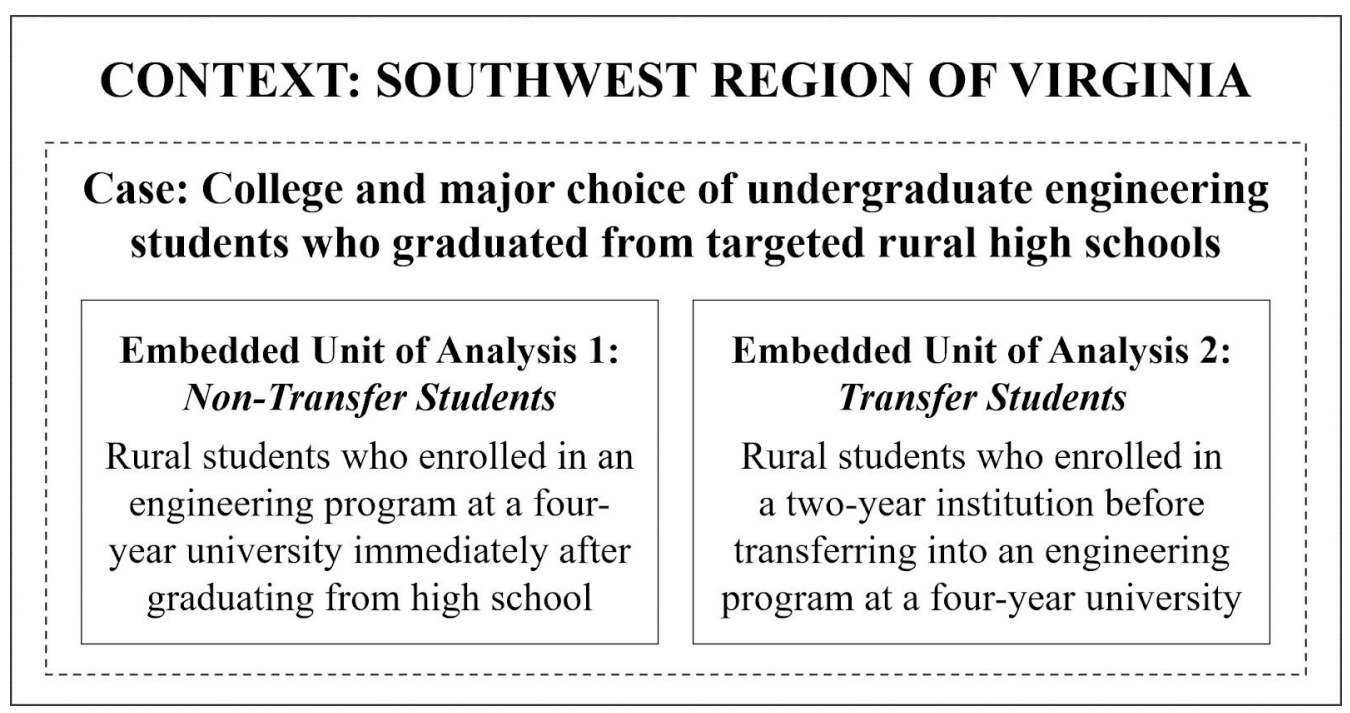

Figure 3. Single-case embedded design

\section{Participants and Data Collection}

[University Name] is a large land-grant, public university in the southeastern United States, with an undergraduate enrollment of over 25,000 students, 7 colleges, and 65 different majors. The College of Engineering represents approximately $30 \%$ of the undergraduate population and offers 14 different majors. The high schools chosen as data sites were drawn from data supplied by the Office of Undergraduate Admissions at [University Name] that summarized admission trends in the four years prior to when the research began (2013-2016). We chose students who graduated from high schools with the highest number of students enrolled in the College of Engineering or transferred to [University Name] from community colleges in regions 6 and 7 as defined by the Virginia Department of Education (VDOE, see Figure 4).

\begin{tabular}{lr}
\hline Variable & N (\%) \\
\hline Admit Type & \\
First-year & $20(55.6 \%)$ \\
Transfer & $16(44.4 \%)$ \\
\hline Gender & \\
Male & $24(66.7 \%)$ \\
Female & $12(33.3 \%)$ \\
\hline First-Generation Status \\
No & $28(77.8 \%)$ \\
Yes & $8(22.2 \%)$ \\
\hline URM Status & \\
Non-URM & $35(97.2 \%)$ \\
URM & $1(2.8 \%)$ \\
\hline
\end{tabular}

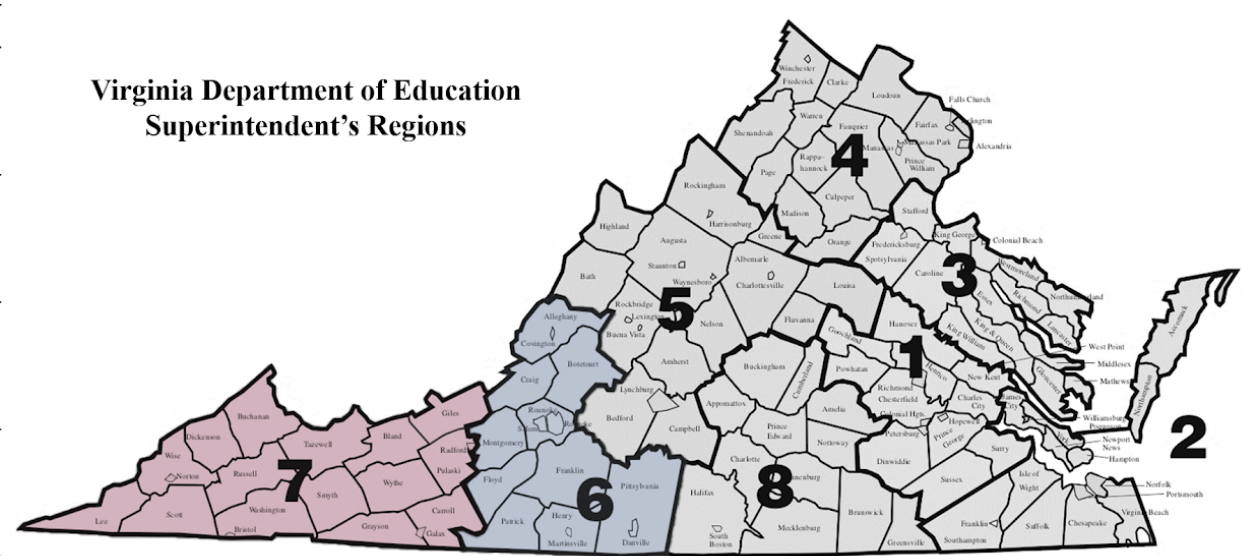

Figure 4. Participant Information and VDOE Superintendent's Regions

We conducted individual interviews with thirty-six participants, sixteen (44\%) of which attended community college before transferring into an engineering program at [University Name]. Institutional data indicates that $33 \%$ of our participants were female, $3 \%$ were an underrepresented minority (URM) in engineering, and 22\% were first-generation college 
students (see Figure 4). The interviews followed a semi-structured format and aimed to understand (1) how and why participants chose to attend community college/[University Name] in general and major in engineering specifically, (2) the community-level influences that supported or hindered their postsecondary enrollment decisions, and (3) general perceptions regarding how their community portrays postsecondary education options and engineering careers as well as who should/should not pursue such aspirations.

\section{Data Analysis}

Data analysis of interview transcripts began with a priori coding, allowing for other codes to emerge throughout the coding process [6]. The a priori codes were generated from Perna's model of student college choice [4] and were grouped within the five layers of the model: Human Capital Investment Model, habitus, school and community context, higher education context, and social, economic, and policy context. All 36 interview transcripts were coded using the qualitative data analysis software Dedoose. The codes were used to identify salient themes and summarize student experiences within the five levels of Perna's model.

\section{Results}

Several key influences on rural students' decision to attend college and pursue engineering as a major emerged across the responses, primarily academic achievement and preparation, parents, school personnel, and characteristics of higher education institutions.

Academic achievements were often cited as the primary reason for choosing to enroll in college and some high achieving students even felt as though going to college was the only option for them. This sentiment was prevalent among transfer and non-transfer participants. Many transfer students shared that they graduated high school in the top of their class, indicating that their academic credentials were not the reason they enrolled in community college rather than a four-year university. Academic achievements in math and science also influenced students' decision to major in engineering. While most participants were high achievers in high school, almost all of them were concerned about their academic preparedness in some areas, specifically related to technical/engineering knowledge, study skills, and personal accountability/responsibility. For example, students felt they were at a disadvantage in their introductory engineering courses because their peers from larger high schools completed computer science and engineering coursework before going to college.

Most transfer (90\%) and non-transfer (69\%) participants indicated their parents were a primary influence on their decision to attend college. Parents' educational attainment is often used as a proxy for cultural capital and the majority of participants in this study had at least one parent who attained a bachelor's degree or higher (approximately $85 \%$ of non-transfer and $69 \%$ of transfer participants). Most of these participants shared that their parents had completed college and encouraged/expected them to do the same. Parents supported participants through involvement in their education, assistance with accessing important resources, and providing information about college. Parental influences appeared more frequently in interviews with non-transfer students, compared to transfer students. 
School personnel and social connections outside of school served as transmitters of social capital for all participants. These individuals provided participants with information about college, assisted with college processes, helped them prepare academically for college, encouraged them to consider engineering as a major, and exposed them to information about engineering careers. Within schools, teachers were the primary source of social capital. Most participants expressed that their guidance counselors were unwilling/unable to provide information about college or assist with college-related processes. The overall impression was that the primary role of guidance counselors was scheduling and paperwork. Outside of school, family, connections through family social networks, and peers were sources of social capital for participants.

The culture and characteristics of higher education institutions also influenced student college choice. The reputation and quality of the academic programs in the College of Engineering was a primary influence on participants' decision to attend [University Name]. Other institutional characteristics influencing student college choice included location/proximity to home, personal and social fit, and affordability/in-state tuition. The proximity of [University Name] to their hometown was particularly important for transfer participants. In addition, community college characteristics influenced college choice for transfer students, specifically affordability (i.e., lower tuition, community college access programs, ability to live at home) and personal/social fit (i.e., close to home, small class sizes).

The key difference in the decision-making process of transfer and non-transfer students was that transfer students tended to view college as an investment in their future. Transfer students frequently discussed the costs and benefits of higher education but very few non-transfer students were influenced by these factors. Several transfer students were concerned about the cost of higher education and shared that their parents were unwilling or unable to contribute. In this study, 50 percent of transfer participants cited lower costs as the primary reason they attended a community college prior to enrolling at a four-year university. However, they often indicated that they were willing to invest in higher education because of the benefits associated with an engineering degree (job opportunities, job satisfaction, and higher earnings). Further, some transfer participants recognized the opportunity costs associated with the two postsecondary pathways, such as missing out on the typical college experience.

\section{Phase 2: Exploring Community Perspectives}

In Phase 2, we used the findings from Phase 1 to conduct interviews with key individuals from the students' high schools and home communities (e.g. teachers, guidance counselors, community leaders, local engineers). Following Yin [5], we conducted a single-case study with three rural communities as the embedded units of analysis. This phase was critical not only for allowing us to triangulate students' perceptions with the perceptions and practices of others, but also for allowing us to understand the goals, attitudes, and experiences of school personnel and local community members as they work with students. 


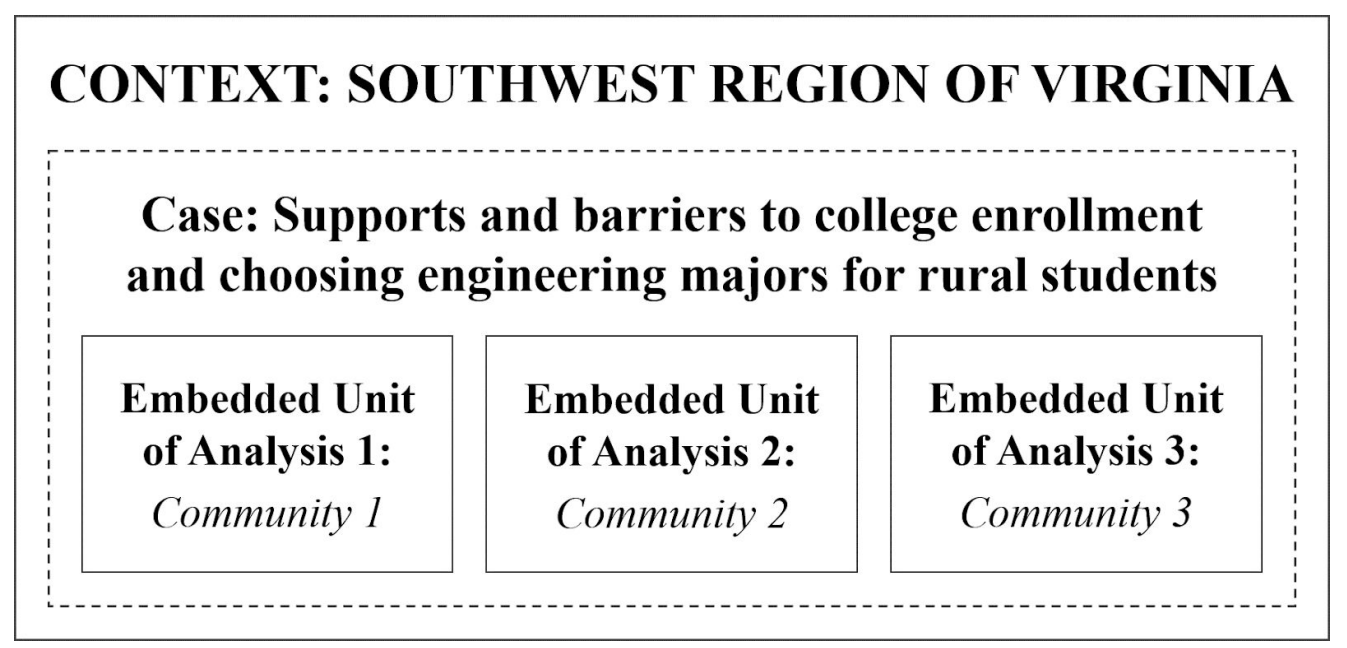

Figure 5. Phase 2 single-case embedded design

\section{Participants and Data Collection}

Based on the findings from student interviews conducted in Phase 1, we developed an interview protocol and identified three rural communities to explore further. We used snowball sampling to reach out to community members and organizations that emerged as salient in students' experiences. In addition, in each community the high school principal, guidance counselors, teachers, personnel from other local education institutions (e.g., Governor's schools, career and technical schools, community colleges), the director of education, relevant members of town government (e.g., chamber of commerce head, cooperative extension agent), and local engineers were recruited to participate in interviews.

We conducted individual interviews with fourteen community members, five from community 1 , four from community 2 , and five from community 3 . The participants were associated with public high schools, Governor's schools, community colleges, technical education centers, Virginia Cooperative Extension, and the chamber of commerce. The interviews followed a semi-structured format and aimed to understand (1) opportunities or experiences in their community that help students explore options after high school and engineering specifically, (2) barriers that might prevent students in their community from going to college and/or choosing engineering majors, and (3) how [University Name] can be a better partner and a better land-grant institution.

\section{Data Analysis}

Analysis of the interview transcripts in Phase 2 also followed the practices outlined in Miles, Huberman, and Saldaña [6], beginning with a priori coding guided by the Perna's model and our research questions, but allowing other descriptive codes to emerge from the data. We began with within-case analysis and then analyzed across embedded units [6] with each community as an embedded unit of analysis, as noted above. All 36 interview transcripts were coded using the qualitative data analysis software Dedoose. Coding sought to identify community resources that 
serve as key supports (e.g., available employment, civic programs) as well as barriers that hinder support and strategies for addressing those barriers.

\section{Results}

Community members who participated in interviews for Phase 2 discussed several supports and barriers to higher education, some of which were consistent with student perceptions from Phase 1. For example, supportive families and dual enrollment courses were often mentioned as supports for students. In addition, several participants discussed the benefits of community college access programs and the guaranteed admissions agreement between community colleges and four-year universities for students considering the community college pathway. However, community members had more to share about community activities available to students through the school or local organizations, including career fairs, assistance with FASFA forms, STEM activities (robotics club, STEM camps, etc.), and career coaches. They also had a more systematic view of the barriers that students might face to higher education and engineering majors, such as low high school graduation rates, concerns about the cost of higher education, and lack of exposure to career options, particularly in engineering. The primary suggestion for how [University Name] can be a better partner and help address some of these barriers was to increase their presence in rural communities. Exposure to university information (majors and opportunities available), and engineering fields specially would better ensure that rural students are able to make informed choices about postsecondary education and engineering as a potential career choice.

\section{Phase 3: Making Connections Through Participatory Design}

For the past few years, our research team has been working with students and community members in rural areas to better understand the supports and barriers around engineering as a potential career choice from a community perspective. We used this information to identify two focus groups for participatory design workshops: extension agents for the Virginia Cooperative Extension and community college faculty and staff. In these workshops, we will provide a brief overview of our findings from Phase 1 and 2, however, they are designed to foster collaborative dialogue among the participants. We will promote discussion among the participants to learn more about how they see their role in supporting students' post-high school plans and career options and collaboratively brainstorm some ways to help rural students learn more about engineering so that they can make informed decisions about whether it is a career they would be interested in pursuing.

\section{Acknowledgements}

This material is based upon work supported by the National Science Foundation under Grant Number [redacted]. Any opinions, findings, and conclusions or recommendations expressed in this material are those of the author(s) and do not necessarily reflect the views of the National Science Foundation. We also wish to thank [redacted] and [redacted] for help with data collection. 


\section{References}

[1] C. Carrico, H. M. Matusovich, and M. C. Paretti, "A qualitative analysis of career choice pathways of college-oriented rural central Appalachian high school students," Journal of Career Development, 2017.

[2] C. A. Carrico, "Voices in the mountains: A qualitative study exploring factors influencing Appalachian high school students' engineering career goals," Ph.D. dissertation, Engineering Education, Virginia Polytechnic Institute and State University, Blacksburg, VA., 2013.

[3] M. Boynton, "People not print: Exploring engineering future possible self-development in rural areas of the Cumberland Plateau," Ph.D. dissertation, Engineering Education, Virginia Polytechnic Institute and State University, Blacksburg, VA., 2014.

[4] L. W. Perna, "Studying college choice: A proposed conceptual model," in Higher Education: Handbook of Theory and Research, vol. 21, J. C. Smart, Ed. New York, NY: Springer, 2006, pp. 99-157.

[5] R. K. Yin, Case study research: Design and methods, 4th ed. Thousand Oaks, CA, Sage Publications, 2009.

[6] M. B. Miles, A. M. Huberman, and J. Saldaña, Qualitative data analysis: A methods sourcebook, 3rd ed. Thousand Oaks, CA, Sage Publications, 2013. 